\title{
Endoscopic transmural hydro-dissection as a rescue therapy for rectal fibrotic adenoma
}

The rectum is considered a feasible and safe area in which to perform endoscopic submucosal dissection (ESD) [1,2]. Therefore, ESD is a suitable approach for the treatment of high risk rectal adenomas. However, scarred and fibrotic polyps have recently been described as the only preoperative predictor of failed ESD in the rectum [2,3]. Transanal endoscopic microsurgery (TEM) has been shown to be an effective treatment for lower rectal carcinomas staged as $\mathrm{T} 1$ or T2 [4], owing to the depth of the resection.

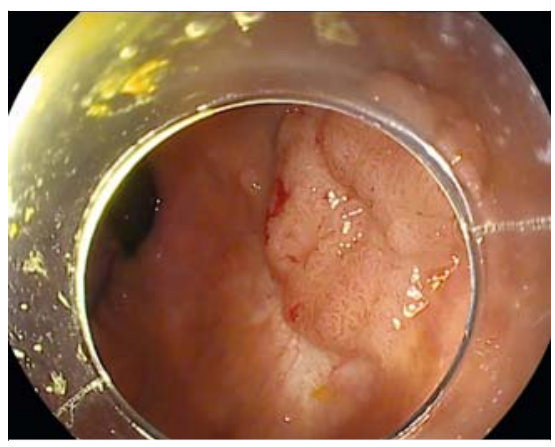

- Fig. 1 Intensely scarred adenoma located $3 \mathrm{~cm}$ away from the dentate line.
We present the case of a $25 \mathrm{~mm} 0$-Is type adenoma with wide scarred areas caused by two previous failed TEMs, located $3 \mathrm{~cm}$ away from the dentate line ( $\triangleright$ Fig. 1 ), in a 75-year-old man without any relevant medical history.

The pocket creation method was adopted because of the expected submucosal fibrotic tissue [5]. The first stage of the tunnel was created without any drawbacks using an Erbejet-2-HybridKnife (Erbe Elektromedizin $\mathrm{GmbH}$, Tübingen, Germany). However, when the area below the lesion was reached, dramatic fibrotic tissue became visible. This finding made it extremely difficult to identify

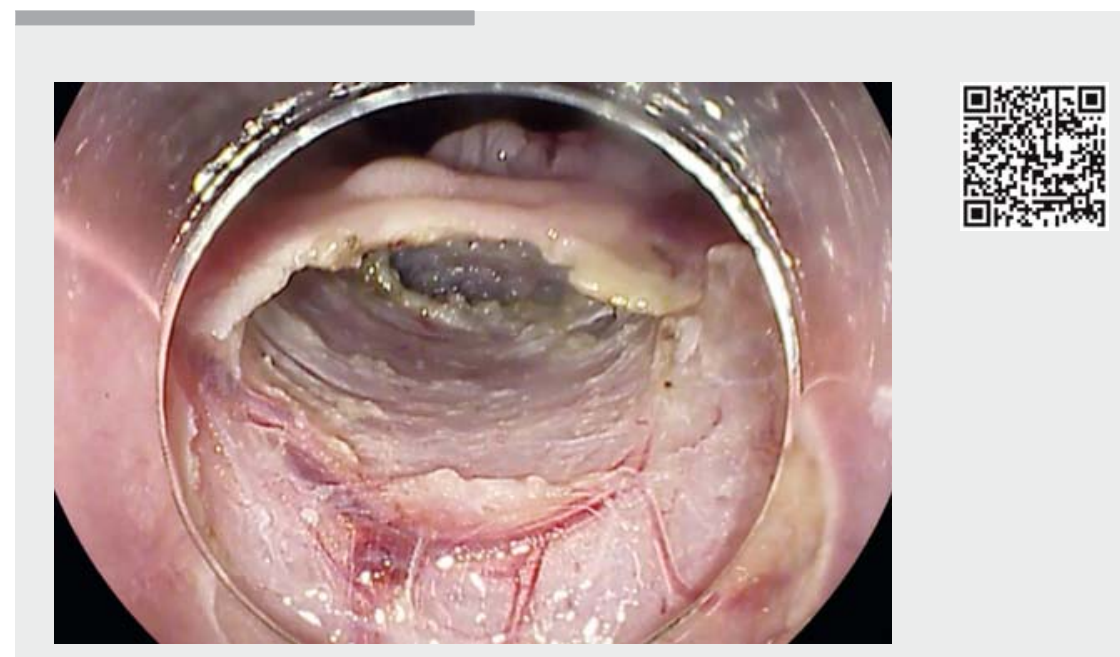

$\checkmark$ Video 1 Endoscopic transmural hydro-dissection by pocket creation method of a sessile scarred polyp located in the lower rectum.

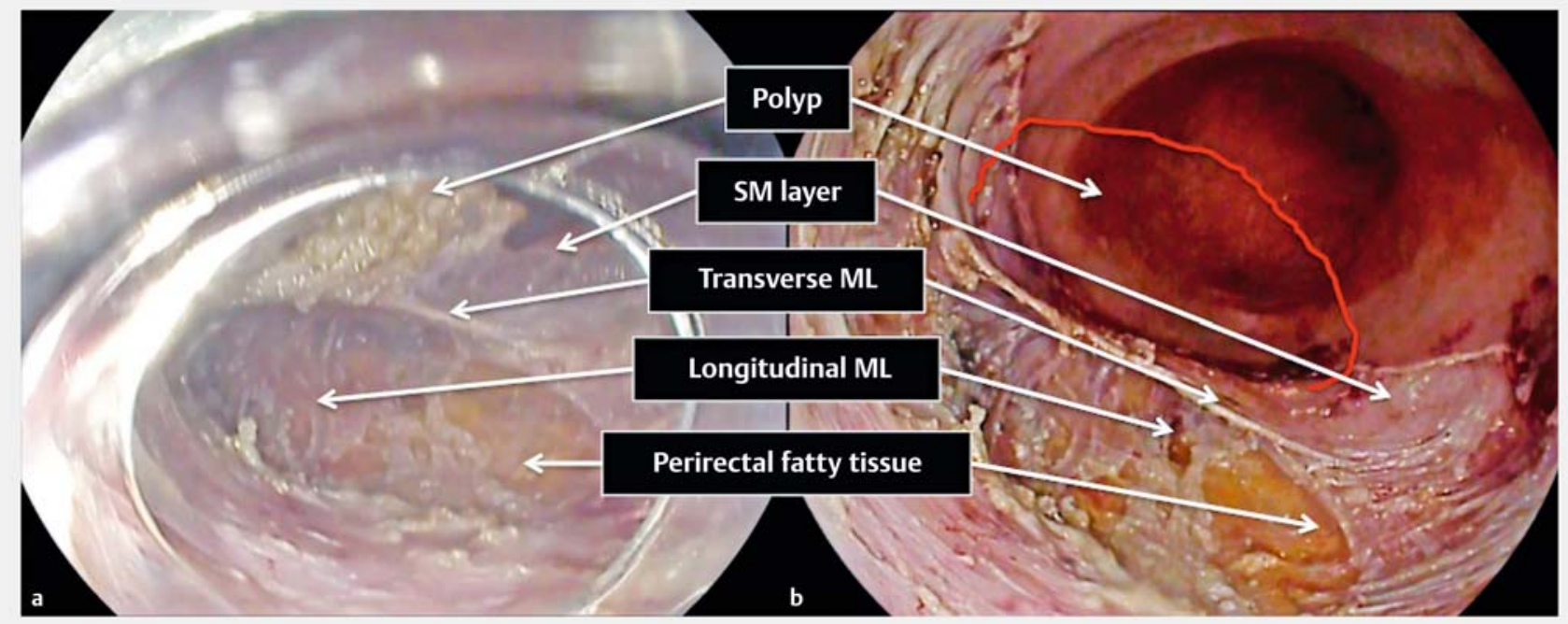

Fig. 2 Transmural dissection planning diagram. a Different layers exposed during the procedure. $\mathbf{b}$ Final result. Red line indicates the previous location of the adenoma. SM, submucosal layer; ML, muscular layer. 

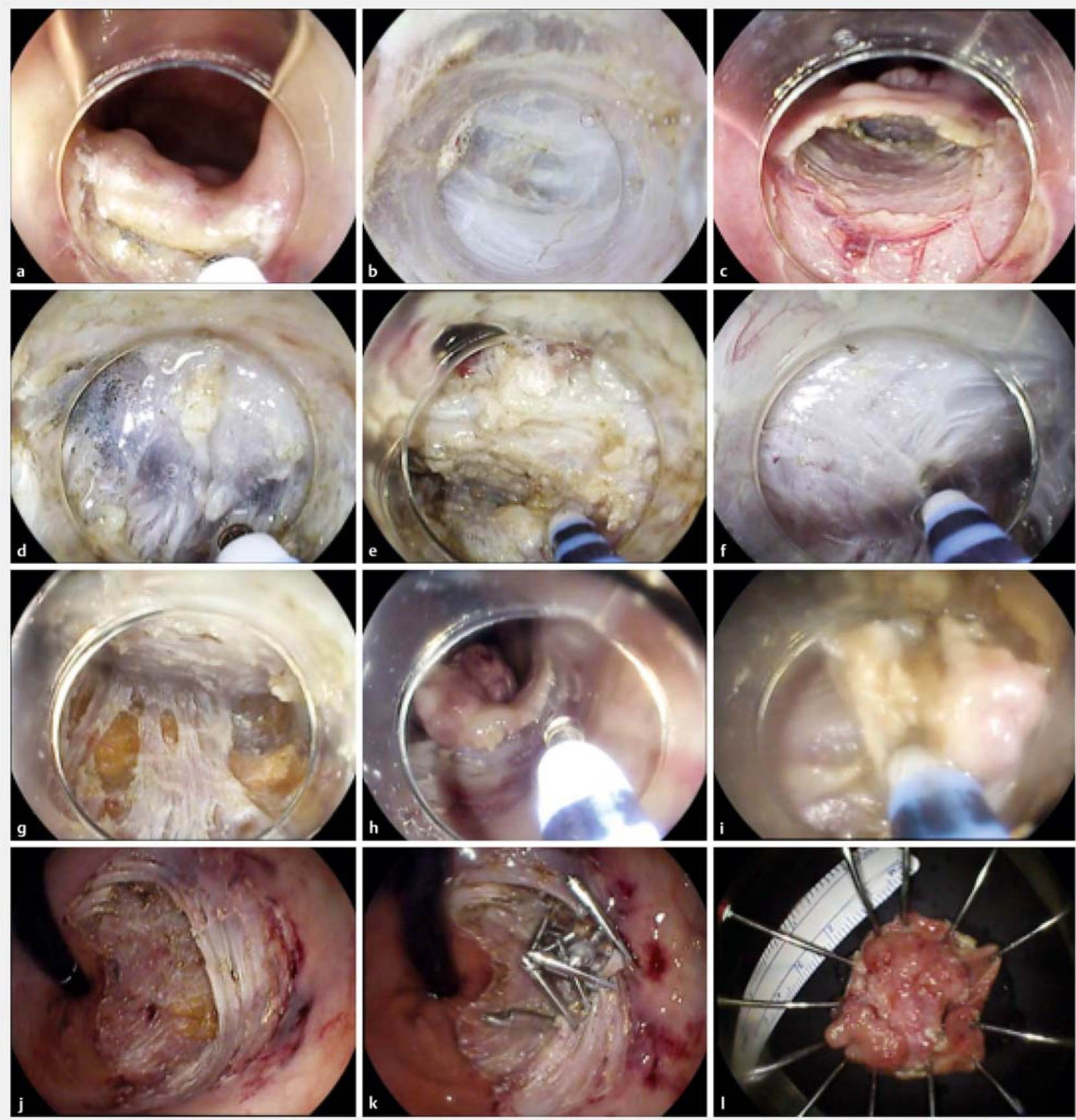

Fig. 3 Detailed endoscopic transmural hydro-dissection procedure. a - c Initial step: tunnel creation across the submucosal layer. $\mathbf{d}$ Submucosal and muscular layer fusion without a feasible traditional cutting line. e Cutting of transverse and longitudinal muscular layer. $\mathbf{f}$ Dissection phase between transverse and longitudinal layer. $\mathbf{g}$ Remaining longitudinal muscular layer and perirectal fatty tissue exposed inside the tunnel. $\mathbf{h}$ Endoscopic submucosal dissection in retroflex position across the submucosal layer. i-k Final dissection steps. I Specimen mounted onto cork.

a feasible cutting line between the submucosal and muscular layers. At this point (stage 2), we decided to carry out a transmural dissection between the transverse and longitudinal muscular layers, in order to reach a feasible cutting line inside the submucosal layer ( $\bullet$ Fig. 2 , $\checkmark$ Fig. 3, V Video 1). Consequently, we successfully achieved en bloc resection of the lesion (stage 3). Subsequently, the muscular defect was closed using endoclips (Resolution; Boston Scientific, Marlborough, Massachusetts, USA). The patient was discharged 72 hours after the procedure. 


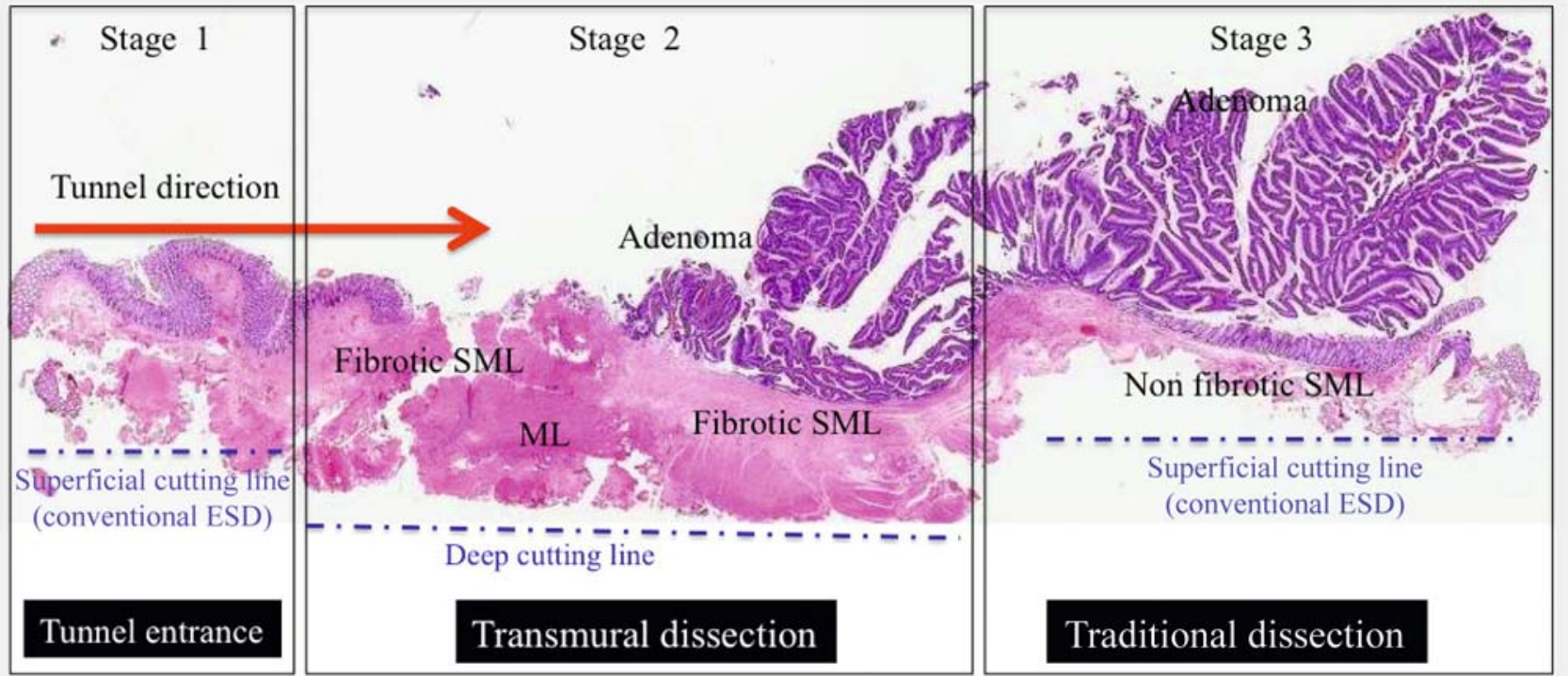

Fig. 4 Microscopic analysis of the dissected specimen, focusing on the different stages of the procedure. SML, submucosal layer; ML, muscular layer.

allowed a safe and deep dissection across muscular layers. This approach might support ESD as a rescue therapy following failed TEM.

Endoscopy_UCTN_Code_TTT_1AO_2AG

Competing interests

None

The authors

Joaquín Rodríguez Sánchez ${ }^{1}$, Eva de la Santa Belda ${ }^{1}$, Lucia González López², Carlos Sánchez García', Bartolomé López Viedma', José Olmedo Camacho ${ }^{1}$

1 Gastrointestinal Endoscopy Unit, Hospital General Universitario de Ciudad Real, Ciudad Real, Spain

2 Pathology Department, Hospital General Universitario de Ciudad Real, Ciudad Real, Spain
Corresponding author

Joaquín Rodríguez Sánchez, MD, PhD

Gastrointestinal Endoscopy Unit, Hospital

General Universitario de Ciudad Real,

C/Obispo Rafael Torija s/n, Ciudad Real

13005, Spain

Fax: +34-926-278000

joakinrodriguez@gmail.com

\section{References}

[1] Pimentel-Nunes P, Dinis-Ribeiro M, Ponchon $T$ et al. Endoscopic submucosal dissection: European Society of Gastrointestinal Endoscopy (ESGE) guideline. Endoscopy 2015; 47 : 829-854

[2] lacopini F, Saito Y, Bella A et al. Colorectal endoscopic submucosal dissection: predictors and neoplasm-related gradients of difficulty. Endosc Int Open 2017; 5: E839E846

[3] Hong SN, Byeon JS, Lee BI et al. Prediction model and risk score for perforation in patients undergoing colorectal endoscopic submucosal dissection. Gastrointest Endosc 2016; 84: $98-108$

[4] Sajid MS, Farag S, Leung P et al. Systematic review and meta-analysis of published trials comparing the effectiveness of transanal endoscopic microsurgery and radical resection in the management of early rectal cancer. Colorectal Dis 2014; 16: 2 - 14
[5] Sakamoto H, Hayashi Y, Miura Y et al. Pocket-creation method facilitates endoscopic submucosal dissection of colorectal laterally spreading tumors, non-granular type. Endosc Int Open 2017; 5: E123 -E129

\section{Bibliography}

DOI https://doi.org/10.1055/s-0044-101598

Published online: 21.2.2018

Endoscopy 2018; 50: E121-E123

(c) Georg Thieme Verlag KG

Stuttgart · New York

ISSN 0013-726X

\section{ENDOSCOPY E-VIDEOS}

https://eref.thieme.de/e-videos

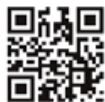

Endoscopy E-Videos is a free access online section, reporting on interesting cases and new techniques in gastroenterological endoscopy. All papers include a high quality video and all contributions are freely accessible online.

This section has its own submission website at https://mc.manuscriptcentral.com/e-videos 